\title{
CONDIÇÕES HIGIÊNICO-SANITÁRIAS E COMPOSIÇÃO NUTRICIONAL DE SALAMES ARTESANAIS E INDUSTRIALIZADOS: UMA COMPARAÇÃO
}

\author{
Débora Francielly De Oliveira ${ }^{1}$ \\ Francieli Braghini ${ }^{2}$ \\ José Francisco Dos Santos Silveira Júnior ${ }^{2}$ \\ Alexandre Rodrigo Coelho ${ }^{3}$ \\ Ivane Benedetti Tonial ${ }^{3}$
}

OLIVEIRA, D. F. de; BRAGHINI, F.; SILVEIRA JÚNIOR, J. F. dos S.; COELHO, A. R.; TONIAL, I. B. Condições higiênico-sanitárias e composição nutricional de salames artesanais e industrializados: uma comparação. Arq. Cienc. Saúde UNIPAR, Umuarama, v. 18, n. 3, p, 151-156, set/dez. 2014.

\begin{abstract}
RESUMO: O salame tipo colonial é um produto de grande aceitação na região sudoeste do Paraná, especialmente, por fazer parte da tradição de origem italiana e pela cultura na produção de suínos. Tradicionalmente, o salame tipo colonial é produzido de forma artesanal, no próprio domicílio ou pequenas indústrias, sendo comercializado em feiras, supermercados e bancas de produtos coloniais em rodovias. A contaminação desses produtos pode ser proveniente da utilização de matérias-primas contaminadas ou por manipulação inadequada antecedente ao consumo. O fato de, normalmente, o produto ser consumido sem cozimento prévio, pode ser considerado um potencial risco a saúde do consumidor. Com o intuito de conhecer a qualidade dos salames coloniais e salames industrializados comercializados na região sudoeste paranaense, realizou-se análises físico-químicas e microbiológicas. Os resultados demonstraram que, enquanto os salames industrializados se encontravam de acordo com a legislação brasileira quanto aos parâmetros físico-químicos e microbiológicos, os salames artesanais apresentaram teores de umidade e de proteínas em discordância com a legislação pertinente, bem como 16,67\% das amostras apresentaram-se contaminadas por Coliformes a $45^{\circ} \mathrm{C}$ e $22,22 \%$ por Salmonella ssp., indicando que é um problema sanitário que carece atenção em nível nacional, uma vez que em estudos anteriores, ficou comprovada a contaminação de salames artesanais de várias regiões do país por microrganismos patogênicos.
\end{abstract}

PALAVRAS-CHAVE: Salame "tipo" colonial; Produção artesanal e industrial.

\section{CONDITIONS SANITARY AND NUTRITIONAL QUALITY OF HANDMAD SALAMI AND INDUSTRIALIZED: A COMPARACTION}

\begin{abstract}
Colonial-type salami is a widely accepted product in the southwestern region of Paraná, especially as part of the Italian tradition and its culture in pig production. Traditionally, the colonial-type salami is handmade in the farmer's house or in small industries, being marketed in fairs, supermarkets and colonial product stands along the roads. The contamination of these products can happen due to the use of contaminated raw materials or by poor handling prior to consumption. The fact that the product is usually consumed without prior cooking can be considered a potential risk to consumer's health. In order to evaluate the quality of industrialized salami and colonial salami marketed in the southwestern region of Paraná, a physical-chemical and microbiological analysis was performed. The results showed that while the industrial salami was manufactured in accordance with the Brazilian law regarding the physical-chemical and microbiological parameters, the handmade salami presented moisture and protein levels in disagreement with the relevant legislation, as well as $16.67 \%$ of the samples presented contamination by coliforms at $45^{\circ} \mathrm{C}$. They also presented $22.22 \%$ of the samples contaminated by Salmonella spp., indicating that this is a health issue that needs to be addressed at a national level, since it can be seen in previous studies that handmade salami presented contamination by pathogenic microorganisms in several regions of the country.

KEYWORDS: Colonial-type salami; Handmade and industrial production.
\end{abstract}

\section{Introdução}

A carne, no que se refere à alimentação humana, é considerada indispensável para uma dieta saudável uma vez que é uma importante fonte de proteína de altíssimo valor biológico, além de ser fonte de vitaminas A e B2, e minerais como cálcio, ferro e fósforo (PHILIPPI, 2003; DALLA SANTA, 2008).

Segundo Dalla Santa (2008) o consumo de produtos cárneos tem aumentado nos últimos anos e como forma de estender a vida-de-prateleira destes alimentos passou-se a industrializá-los. A industrialização e o processamento de carnes consistem na transformação das carnes em produtos cárneos, destacando-se as linguiças, mortadela, salsicha, apresuntado, presunto, hambúrguer, charque e salames.

A fabricação de salames foi provavelmente uma das primeiras formas de processamento da carne que datam de tempos babilônicos, quando métodos como a secagem, a salga e a fermentação já estavam em uso (FRANCO; LANDGRAF, 2002). A fermentação é um método simples e barato de preservação de produtos cárneos, com a vantagem de criar produtos característicos e com sabor e aroma característicos (SAKHARE; RAO, 2003).

No Brasil a produção de salames surgiu por meio de processos trazidos pelos imigrantes italianos, feitos de forma colonial, que, mais tarde transformaram-se em pequenas fábricas (VIOTTI STOLBERG, PELISSER, 2006).

O salame é, portanto, definido como um produto embutido cru, que consiste da mistura de carne crua de suíno ou de suíno e bovino, adicionado de toucinho, sais, agentes de cura e temperos, embutido em envoltórios naturais (tripas) ou artificiais (sintéticas), curado, fermentado, maturado,

DOI: https://doi.org/10.25110/arqsaude.v18i3.2014.5190

${ }^{1}$ Profa. do Departamento de Engenharia de Alimentos - Universidade Federal de Rondônia (UNIR). *Autor para correspondência: debora.oliveira@unir. Avenida Tancredo Neves, 3450 - Setor Institucional, CEP: 76 872-862, Ariquemes, Rondônia, Brasil. Fone: (69) 3535-3563.

${ }^{2}$ Mestrandos em Ciência e Tecnologia de Alimentos - Universidade Federal de Santa Catarina (UFSC).

${ }^{3}$ Professores do Departamento de Tecnologia de Alimentos - Universidade Tecnológica Federal do Paraná (UTFPR). 
dessecado e submetido ou não a defumação (MILANI et al., 2003), comumente consumidos sem aquecimento.

Para Franco e Landgraf (2002), a manipulação adequada da matéria-prima, a correta sanitização dos equipamentos e a higiene dos manipuladores, são fatores importantes que estão ligados diretamente à qualidade dos embutidos crus. Ordoñez et al. (2005) complementam que quando há contaminação inicial, a segurança do produto poderá ficar comprometida e este pode se tornar um veículo de patógenos de origem alimentar.

Considerando o grande consumo no sudoeste do Paraná, as possíveis contaminações durante processamento do salame artesanal e a sua forma de consumo, objetivou-se avaliar a qualidade microbiológica e físico-química de salames coloniais produzidos de formas artesanal e comparar a sua qualidade com salames industrializados.

\section{Material e Método}

\section{Amostragem}

Realizou-se 10 coletas de 6 diferentes marcas de salames, sendo 3 marcas de salame colonial e 3 marcas de salame industrializado, totalizando 30 amostras de salame artesanal e 30 amostras de salame industrializado. As amostras foram coletadas em diferentes municípios do sudoeste paranaense e acondicionadas em caixas isotérmicas, nas quais foram transportadas para o complexo de laboratórios de alimentos da Universidade Tecnológica Federal do Paraná - Campus Francisco Beltrão-Pr.

Para a realização das análises, padronizou-se um período de 21 dias após a fabricação de todas as amostras de salames analisadas.

\section{Avaliação microbiológica}

Foram coletadas porções de $25 \mathrm{~g}$ de salame, as quais foram homogeneizadas com $225 \mathrm{~mL}$ de água peptonada $(0,1 \%)$ em Bag Mixer, por 2 minutos. Em seguida, foram feitas sucessivas diluições decimais.

\section{Contagem de bactérias ácido lácticas}

A contagem de bactérias láticas foi realizada utilizando ágar de Man, Rogosa e Sharpe - MRS. As placas foram incubadas à temperatura de $+37^{\circ} \mathrm{C}$ por 5 dias. Foram feitas semeaduras em duplicata para cada diluição, sendo a superfície das placas recoberta com uma sobrecamada do mesmo meio para geração de uma atmosfera microaerófila (SIQUEIRA, 1995).

\section{Coliformes a $45^{\circ} \mathrm{C}$}

Para a determinação de coliformes totais foi utilizada a técnica do plaqueamento por incorporação do meio de cultura ágar cristal violeta vermelho neutro bile com incubação a $37^{\circ} \mathrm{C}$, por 24 horas. A partir das placas com desenvolvimento de coliformes totais foram determinados os coliformes fecais em caldo EC (BRASIL, 2003).

\section{Salmonella ssp.}

Realizou-se um pré-enriquecimento em água peptonada tamponada a $37^{\circ} \mathrm{C}$ por 24 horas a partir de $25 \mathrm{~g}$ das amostras. Após essa etapa, foi feito um enriquecimento seletivo em caldo Tetrationato Verde Brilhante e Rappaport Vas- siliadis e foram levados à estufa por 24 horas, a $42,5^{\circ} \mathrm{C}$. A partir destes, semeou-se uma alíquota em placas com ágar SS (Salmonella Shiguella) e ágar Rambach, e foram incubados a $37^{\circ} \mathrm{C}$, por 24 horas. As colônias típicas de cada placa foram semeadas em tubos de ágar estoque; caldo ureia; ágar lisina ferro (LIA); ágar citrato de simmons; SIM, para motilidade do indol; ágar tríplice açúcar ferro (TSI), para confirmação bioquímica (BRASIL, 2003).

\section{Staphylococcus coagulase positiva}

A análise de Staphylococcus coagulase positiva foi determinada de acordo com Brasil (2003), utilizando-se Ágar Baird-Parker a $37^{\circ} \mathrm{C}$, por 48 horas. Em seguida, foi realizado o bioquímico da coagulase com plasma de coelho.

\section{Análises físico-químicas}

\section{Determinação do pH}

A medição do $\mathrm{pH}$ foi feita por meio da homogeneização de dez gramas da amostra com água destilada (1:10 amostra/água). O homogeneizado foi submetido aos eletrodos do pHmetro Digimed, por cinco minutos, quando foi procedida a leitura do $\mathrm{pH}$ (TERRA; BRUM, 1988).

\section{Determinação da atividade de água (Aw)}

Para determinação da atividade de água do salame foi utilizado o aparelho Testo 650 (modelo 0563 6501) conforme utilizado por Cirolini et al. (2010).

\section{Determinação de nitrito}

A determinação de nitrito das amostras foi realizada conforme método descrito por Association of Official Analytical Chemists (1996).

\section{Determinação da composição centesimal}

Por meio de técnicas da Association of Official Analytical Chemists (1996), determinou-se o percentual de umidade, cinzas e proteína, enquanto que os percentuais de lipídios totais foram determinados de acordo com metodologia de Bligh e Dyer (1959) e os percentuais de carboidratos totais mediante cálculo da diferença entre $100 \mathrm{~g}$ da amostra e a soma do conteúdo de proteínas, gorduras, umidade e cinzas descrita por Simões et al. (2009).

\section{Análise estatística}

Os resultados físico-químicos foram submetidos à análise de variância (ANOVA), a 5\% de probabilidade, pelo teste de Tukey, pro meio do software Statistica, versão 7.0 (2004).

\section{Resultados e Discussão}

Os valores médios dos parâmetros físico-químicos dos salames colonial (artesanal) e industrializado comercializados no sudoeste do Paraná estão apresentados na Tabela 1. 
Tabela 1: Resultados físico-químicos médios de salames artesanais e industrializados.

\begin{tabular}{|c|c|c|c|c|c|c|}
\hline \multirow[b]{2}{*}{ Parâmetros } & \multicolumn{3}{|c|}{ Salames artesanais } & \multicolumn{3}{|c|}{ Salames industrializadas } \\
\hline & $\mathbf{A}$ & B & $\mathbf{C}$ & $\mathbf{A}$ & B & $\mathrm{C}$ \\
\hline $\mathrm{pH}$ & $\begin{array}{c}5,35 \pm 0,09^{\mathrm{a}} \\
\quad \mathrm{CV}(\%) 0,02\end{array}$ & $\begin{array}{l}5,32 \pm 0,11^{\mathrm{a}} \\
\quad \mathrm{CV}(\%) 0,02\end{array}$ & $\begin{array}{l}5,48 \pm 0,08^{\mathrm{a}} \\
\quad \mathrm{CV}(\%) 0,01\end{array}$ & $\begin{array}{c}4,89 \pm 0,04^{b} \\
\text { CV (\%) } 0,08\end{array}$ & $\begin{array}{c}4,92 \pm 0,04^{b} \\
\text { CV (\%) } 0,08\end{array}$ & $\begin{array}{c}4,92 \pm 0,09^{\mathrm{b}} \\
\mathrm{CV}(\%) 0,02\end{array}$ \\
\hline Aw & $\begin{array}{l}0,88 \pm 0,11^{\mathrm{a}} \\
\quad \mathrm{CV}(\%) 0,12\end{array}$ & $\begin{array}{c}0,87 \pm 0,07^{\mathrm{a}} \\
\operatorname{CV}(\%) 0,08\end{array}$ & $\begin{array}{c}0,88 \pm 0,03^{\mathrm{a}} \\
\quad \mathrm{CV}(\%) 0,03\end{array}$ & $\begin{array}{l}0,81 \pm 0,02^{\mathrm{b}} \\
\quad \mathrm{CV}(\%) 0,02\end{array}$ & $\begin{array}{c}0,82 \pm 0,09^{\mathrm{c}} \\
\mathrm{CV}(\%) 0,10\end{array}$ & $\begin{array}{l}0,82 \pm 0,08^{\mathrm{c}} \\
\quad \mathrm{CV}(\%) 0,09\end{array}$ \\
\hline Nitrito (ppm) & $\begin{array}{c}4,97 \pm 0,19^{\mathrm{a}} \\
\quad \mathrm{CV}(\%) 0,05\end{array}$ & $\begin{array}{c}4,29 \pm 0,12^{\mathrm{b}} \\
\mathrm{CV}(\%) 0,03\end{array}$ & $\begin{array}{c}3,44 \pm 0,21^{\mathrm{c}} \\
\mathrm{CV}(\%) 0,06\end{array}$ & $\begin{array}{l}5,01 \pm 0,17^{\mathrm{a}} \\
\mathrm{CV}(\%) 0,03\end{array}$ & $\begin{array}{c}5,33 \pm 0,14^{\mathrm{a}} \\
\quad \mathrm{CV}(\%) 0,02\end{array}$ & $\begin{array}{c}6,38 \pm 0,24^{\mathrm{d}} \\
\mathrm{CV}(\%) 0,04\end{array}$ \\
\hline Umidade (\%) & $\begin{array}{c}48,12 \pm 0,04^{\mathrm{a}} \\
\quad \operatorname{cV}(\%)\end{array}$ & $\begin{array}{c}47,73 \pm 0,05^{b} \\
\operatorname{CV}(\%)\end{array}$ & $\begin{array}{c}47,75 \pm 0,22^{b} \\
\operatorname{CV}(\%)\end{array}$ & $\begin{array}{c}37,50 \pm 0,02^{\mathrm{c}} \\
\mathrm{CV}(\%)\end{array}$ & $\begin{array}{c}38,23 \pm 0,07^{\mathrm{d}} \\
\mathrm{CV}(\%)\end{array}$ & $\begin{array}{c}38,37 \pm 0,12^{\mathrm{d}} \\
\text { CV }(\%)\end{array}$ \\
\hline Cinzas $(\%)$ & $\begin{array}{l}6,69 \pm 0,21^{\mathrm{a}} \\
\quad \mathrm{CV}(\%) 0,03\end{array}$ & $\begin{array}{c}6,14 \pm 0,03^{\mathrm{ab}} \\
\mathrm{CV}(\%)\end{array}$ & $\begin{array}{c}6,19 \pm 0,02^{\mathrm{ab}} \\
\mathrm{CV}(\%)\end{array}$ & $\begin{array}{c}5,39 \pm 0,04^{\mathrm{cb}} \\
\mathrm{CV}(\%)\end{array}$ & $\begin{array}{l}4,94 \pm 0,01^{\mathrm{c}} \\
\mathrm{CV}(\%)\end{array}$ & $\begin{array}{c}5,91 \pm 0,03^{\text {bc }} \\
\quad \mathrm{CV}(\%)\end{array}$ \\
\hline Proteínas $(\%)$ & $\begin{array}{c}19,75 \pm 0,14^{\mathrm{a}} \\
\quad \mathrm{CV}(\%) 0,07\end{array}$ & $\begin{array}{l}19,85 \pm 0,16^{\mathrm{a}} \\
\quad \mathrm{CV}(\%) 0,08\end{array}$ & $\begin{array}{l}19,94 \pm 0,10^{\mathrm{a}} \\
\quad \mathrm{CV}(\%) 0,05\end{array}$ & $\begin{array}{l}26,10 \pm 0,08^{b} \\
\quad \text { CV (\%) } 0,03\end{array}$ & $\begin{array}{l}26,41 \pm 0,23^{\mathrm{c}} \\
\quad \mathrm{CV}(\%) 0,09\end{array}$ & $\begin{array}{c}26,89 \pm 0,13^{\mathrm{d}} \\
\quad \text { CV (\%) } 0,04\end{array}$ \\
\hline Lipídios (\%) & $\begin{array}{l}24,21 \pm 0,19^{\mathrm{a}} \\
\mathrm{CV}(\%) 0,08\end{array}$ & $\begin{array}{l}23,21 \pm 0,15^{b} \\
\quad \text { CV (\%) } 0,06\end{array}$ & $\begin{array}{l}24,98 \pm 0,09^{c} \\
\text { CV (\%) } 0,04\end{array}$ & $\begin{array}{c}28,57 \pm 0,09^{\mathrm{d}} \\
\mathrm{CV}(\%) 0,03\end{array}$ & $\begin{array}{c}29,09 \pm 0,25^{\mathrm{e}} \\
\mathrm{CV}(\%) 0,08\end{array}$ & $\begin{array}{c}28,33 \pm 0,17^{\mathrm{d}} \\
\mathrm{CV}(\%) 0,06\end{array}$ \\
\hline $\begin{array}{l}\text { Carboidratos } \\
(\%)\end{array}$ & $\begin{array}{c}1,23 \pm 0,01^{\mathrm{a}} \\
\quad \mathrm{CV}(\%) 0,08\end{array}$ & $\begin{array}{c}3,08 \pm 0,02^{\mathrm{b}} \\
\quad \mathrm{CV}(\%) 0,06\end{array}$ & $\begin{array}{l}1,14 \pm 0,01^{\mathrm{a}} \\
\quad \mathrm{CV}(\%) 0,09\end{array}$ & $\begin{array}{l}1,66 \pm 0,02^{\mathrm{a}} \\
\quad \mathrm{CV}(\%) 0,01\end{array}$ & $\begin{array}{l}1,33 \pm 0,01^{\mathrm{a}} \\
\quad \mathrm{CV}(\%) 0,07\end{array}$ & $\begin{array}{l}1,29 \pm 0,01^{\mathrm{a}} \\
\quad \mathrm{CV}(\%) 0,08\end{array}$ \\
\hline
\end{tabular}

Os resultados são médias de 18 replicatas com as respectivas estimativas do desvio padrão. Valores na mesma linha seguidos de letras iguais não diferem entre si (p>0,05), [Análise de variância - ANOVA e Teste de Tukey]. CV = coeficiente de variação = (desvio padrão/ média) x 100 .

Os coeficientes de variação encontrados neste estudo variaram de 0,11 à $0,88 \%$. Os valores do coeficiente de variação até $30 \%$ são considerados normais para respostas obtidas na área biológica, sendo assim, os resultados situam-se dentro de uma faixa de variação normal (SAMPAIO, 1998).

Segundo Terra (2003) e Cirolini et al. (2010), a queda do $\mathrm{pH}$ está diretamente relacionada com o acúmulo de ácido lático, formado pela ação das bactérias ácido láticas sobre os carboidratos presentes na massa cárnea. Embora os resultados demonstrarem que os salames artesanais analisados apresentaram valores de $\mathrm{pH}$ significativamente superiores $(5,32$ a 5,48$)$ aos encontrados para os salames industrializados $(4,89$ a 4,92), estes valores estão de acordo com Ambrosiadis et al. (2004), os quais destacaram que o pH de salames tradicionais varia entre 4,67 a 6,09. De acordo com Franco e Landgraf (2002), salames que apresentam pH dentro dessa faixa pode favorecer o crescimento de Staphylococcus aureus, responsável por parte das intoxicações alimentares vinculadas por estes produtos.

Os valores de atividade de água (Aw) obtidos para as amostras de salames artesanais não diferiram entre si ( $\mathrm{p}<0,05 \%$ ), ficando entre 0,87 e 0,88 , porém, diferiram dos valores observados para os salames industrializados, os quais apresentaram Aw entre 0,81 e 0,82 e também não apresentaram diferença significativa entre si. Esses resultados corroboram com Cavenaghi e Oliveira (1999), os quais destacaram que, nos salames nacionais, a Aw fica em torno de 0,816 e 0,868 , bem como são semelhantes aos encontrados por Cirolini et al. (2010), que verificaram Aw em salames tipo italiano entre 0,80 e 0,87 . De acordo com Chasco, Lizago e Beriain, (1996) e Drosinos et al. (2005), a diminuição da atividade de água do salame pode ser atribuída ao decréscimo nos valores de $\mathrm{pH}$, pois a capacidade de retenção de água das proteínas da carne é diminuída quando o $\mathrm{pH}$ se aproxima do seu ponto isoelétrico, acelerando a desidratação e, consequentemente, a redução da Aw.

Os teores de nitrito residual (entre 3,44 e 6,38 ppm) de ambas as amostras analisadas (salames artesanais e industrializados) estavam de acordo com a Portaria $n^{\circ} 1004$ de 11/12/98 do Ministério da Saúde (BRASIL, 1998), que permite nível máximo residual de nitrito em produtos cárneos de 0,015 g.100 g-1, ou seja, 150 ppm. Valores semelhantes de nitrito residual (entre 3,28 e 6,09 ppm) foram verificados por Cirolini et al. (2010) em salames tipo italiano após 21 dias de fabricação.

A composição centesimal pode ser tomada como base para determinação do valor nutritivo de um alimento e também como parâmetro para avaliar sua qualidade (TERRA; FRIES; TERRA, 2004).

Os resultados mostraram que os salames produzidos de forma artesanal apresentaram maior percentual ( $p>0,05 \%$ ) de umidade quando comparados aos salames industrializados, além de apresentarem-se em desacordo com o Regulamento Técnico de Identidade e Qualidade para salames (BRASIL, 2000), o qual determina um valor máximo de umidade de $40 \%$, enquanto que os salames industrializados apresentaram valores dentro do limite estabelecido pela legislação. A variação nos teores de umidade de salames pode ser consequência da falta de padronização no processo de produção e/ou da maior ou menor presença de gordura na amostra, uma vez que, quanto maior o teor de gordura da amostra, menor tende a ser o seu teor de umidade (SCHEID et al., 2003; VIOTT; STOLBERT; PELISSER, 2003).

A relação entre os teores de lipídios e umidade fica evidenciada ao ser constatado que os salames artesanais apresentaram menores valores de lipídios (entre 23,21 a 24,89\%) e maiores teores de umidade em comparação aos industrializados, que apresentaram maiores valores de lipídios (28,33 a $29,09 \%$ ) e, portanto, menores valores de umidade. Apesar de os percentuais de gordura terem diferido significativamente entre os salames artesanais e industrializados, ambos se 
encontraram em concordância com os valores estipulados no Regulamento Técnico de Identidade e Qualidade para salames, que indica um teor máximo de gordura de 30,0\% (BRASIL 2000).

Os teores de cinzas variaram de 6,14 a $6,69 \%$ para os salames artesanais e de 4,94 a 5,91\% para os salames industrializados, havendo também diferença estatística ( $p>0,05 \%$ ) quanto ao tipo de salame. Em estudo realizado para caracterizar salames tradicionais da Grécia, Ambrosiadis et al. (2004) encontraram teores de cinzas entre 2,13\% e $5,07 \%$, semelhantes aos verificados nesse estudo. Os autores justificaram que a grande variação nos teores de minerais das amostras poderia estar relacionada com as variações no teor de umidade dessas. Para Dalla Santa (2008), a quantidade de sal utilizada nas formulações dos salames também pode contribuir para variação e elevação da quantidade de cinzas no produto.

O percentual de proteínas variou de 19,75 a 19,94\% para o salame artesanal e de 26,10 a $26,89 \%$ para o salame industrializado. A análise dos resultados indica que os salames produzidos de forma artesanal apresentaram conteúdo de proteínas em níveis inferiores aos estipulados pelo Regulamento Técnico e Identidade e Qualidade para salames, o qual estabelece um valor mínimo de proteínas de $20 \%$ para esse tipo de produto (BRASIL, 2000). Ibañez et al. (1997) referem que o baixo conteúdo de proteínas em produtos cárneos pode comprometer seu valor proteico e sua qualidade, uma vez que as proteínas são consideradas os principais componentes funcionais e estruturais de carnes processadas. Vale ressaltar que, quanto menor é o conteúdo de umidade de um alimento, maior é a concentração dos seus demais constituintes, o que permite justificar os maiores teores de proteínas e também de lipídios encontrados para os salames industrializados em comparação aos produtos artesanais.

Os valores encontrados para o percentual de carboidratos variaram de 1,14 a 3,08\% para o salame artesanal e de 1,29 a 1,66\% para o industrializado. Com base nesses resultados, os dois tipos de salame (artesanal e industrializado) apresentaram valores dentro do que é estabelecido pelo Regulamento Técnico de Identidade e Qualidade para salames que estabelece um valor máximo de 4,0\% (BRASIL, 2000).

De acordo com Cirolini et al. (2010), a composição química do salame o torna um excelente meio de cultura para a maioria dos micro-organismos, cuja quantidade e tipos dependem, principalmente, das condições de higiene dos manipuladores, utensílios e das condições de processamento do produto.

Os resultados da contagem de bactérias ácido láticas mostraram que as amostras com a menor concentração tiveram contagens de 4,02 log UFC. $g^{-1}$, entretanto em 75,0\% das amostras (27) a presença de bactérias lácticas foi superior a $6 \log$ UFC.g ${ }^{-1}$, sendo que as amostras com as maiores contagens tiveram valores entre 7,5 log UFC.g-1 e 8,21 log UFC. $\mathrm{g}^{-1}$. Os resultados obtidos neste trabalho são semelhantes aos encontrados por Ambrosiadis et al. (2004), que obtiveram contagens de bactérias ácido láticas em torno de 4 a 8 UFC. $\mathrm{g}^{-1}$ na caracterização de salames artesanais da Grécia e por Dalla Santa (2008), o qual encontrou contagens entre a 4 e 8,35 log UFC. g $^{-1}$ desse mesmo grupo de microrganismo em salames tipo italiano.

Verificou-se que os salames industrializados apre- sentaram maiores concentrações de bactérias ácido láticas em relação aos salames artesanais. A utilização pela indústria de culturas starters como as bactérias ácido lácticas que promovem a segurança e estabilidade do produto e Staphylococccus coagulase negativa, responsáveis por estabilizar a cor, prevenir a rancificação e realçar compostos aromáticos dos produtos cárneos, pode ter contribuído para esse resultado. Soyer e Ertas (2005) descrevem que, a concentração final de bactérias lácticas é dependente da contagem inicial no produto e das condições de produção utilizadas, tais como o binômio temperatura e umidade relativa do ambiente durante a fermentação e maturação. Moretti et al. (2004) verificaram a influência desses fatores utilizando duas condições diferentes de maturação e obtiveram resultados variáveis, com contagens entre 7 e $8 \log$ UFC.g- ${ }^{1}$. Fatores como a variação na quantidade dos componentes principais das formulações (gordura e proteínas) e os condimentos utilizados na formulação também podem contribuir para a variação na concentração final de bactérias ácido láticas em salames (LEROY; DE VUYST, 2004).

Os resultados das análises microbiológicas mostraram que $100,0 \%$ das amostras de salame fabricadas industrialmente, estavam dentro dos padrões estabelecidos pela Resolução RDC no 12 da Agência Nacional de Vigilância Sanitária (BRASIL, 2001), que atribui os seguintes valores máximos para produtos cárneos maturados: ausência de Salmonella sp. em $25 \mathrm{~g}$ de amostra; $10^{3} \mathrm{NMP}^{-g^{-1}}$ de amostra para Coliformes a $45^{\circ} \mathrm{C}$ e $5 \times 10^{3} \mathrm{UFC}^{-1} \mathrm{~g}^{-1}$ de amostra de Staphylococcus coagulase positiva.

Já os resultados obtidos para as amostras de salames coloniais fabricados artesanalmente indicaram que 10,0\% (3) apresentaram coliformes termotolerantes e 16,67\% (5) Salmonella sp., portanto, por estarem fora dos padrões microbiológicos estabelecidos para produtos cárneos maturados (BRASIL, 2001), estavam impróprias para consumo.

Coliformes termotolerantes têm sido utilizados para determinar condições higiênico-sanitárias na produção de alimentos. A presença de Escherichia coli em desacordo com os padrões vigentes pela legislação neste trabalho pode indicar uma possível manipulação sem higiene, armazenamento inadequado à temperatura acima de $4{ }^{\circ} \mathrm{C}$, recontaminação pós-processamento e ainda contaminantes provenientes da matéria-prima. O processo de moagem, pelo qual a carne é submetida, favorece a contaminação por micro-organismos, pois aumenta a superfície de contato e proporciona a incorporação de resíduos de moagens anteriores (ALMEIDA; GONÇALVES; FRANCO, 2002).

O gênero Salmonella representa um grupo de bactérias cujo principal reservatório é o trato gastrintestinal do ser humano e de animais, principalmente. aves e suínos (ALMEIDA et al., 2002). Em estudo realizado por Magro e Klein (2006) ficou comprovada a presença de Salmonella sp em algumas amostras de salames tipo colonial produzidos no sul do país. Dessa forma, ressalta-se a importância do controle da qualidade microbiológica desse tipo de produto, visto que a Legislação Brasileira (BRASIL, 2001) estabelece ausência desta bactéria em alimentos.

Apesar de não terem sido observadas cepas de Staphyloccocus coagulase positiva, a alta incidência (100,0\%) de cepas coagulase negativa nas amostras analisadas de salames artesanais e industrializados, mesmo contribuindo para 
as características de flavor e cor desejáveis no produto, pode ser um indicativo de perigo à saúde pública, devido à possibilidade da produção de enterotoxina estafilocócica e resultar numa intoxicação alimentar estafilocócica (MAGRO; KLEIN, 2006).

\section{Conclusão}

Os resultados físico-químicos e microbiológicos dos salames industrializados demonstraram que 100,0\% das amostras analisadas se apresentaram em conformidade com a legislação brasileira, enquanto que os salames artesanais apresentaram discordâncias com os valores estipulados pelo Regulamento Técnico de Identidade e Qualidade para salames quanto aos teores de umidade e proteínas, além de ter sido constatado que $16,67 \%$ das amostras apresentaram-se contaminadas por Salmonella ssp. e 10,0\% por Coliformes termotolerantes; portanto, impróprias para o consumo humano. Sendo assim, conclui-se que os salames coloniais necessitam de um melhor acompanhamento no processo de produção, no intuito de identificar e sanar a causa das possíveis contaminações por micro-organismos patogênicos.

\section{Referências}

ALMEIDA, A. S.; GONÇALVES, P. M. R.; FRANCO, R. M. Salmonella em corte de carne bovina inteiro e moído. Higiene Alimentar, v. 16, n. 96, p. 77-81, 2002.

AMBROSIADIS, J. et al. Physicochemical, microbiological and sensory attributes for the characterization of greek traditional sausages. Meat Science, v. 66, n. 2, p. 279-287, 2004.

\section{ASSOCIATION OF OFFICIAL ANALYTICAL CHEMISTS. Official methods of analysis of AOAC internacional. 16. ed. v. 2., 1996.}

BLIGH, E. G.; DYER.; W. J. A rapid method of total lipid estraction and purification. Canadian Journal of Biochemistry, v. 37, p. 911-17, 1959.

BRASIL. Ministério da Saúde. Regulamento Técnico Atribuição de Funções de Aditivos, Aditivos e seus Limites Máximos de uso para a Categoria 8 - Carne e Produtos Cárneos. Portaria ${ }^{\circ} 1004,11$ de dezembro de 1998. Diário Oficial da União, Brasília, DF, 14 dez. 1998, p. 28.

BRASIL. Ministério da Agricultura e do Abastecimento. Instrução Normativa $n^{0} 22$ de 31 de junho de 2000, Anexo V. Regulamento Técnico de Identidade e Qualidade de Salame. Diário Oficial da União, Brasília, DF, 3 ago. 2000.

BRASIL. Ministério da Saúde. Agência Nacional de Vigilância Sanitária. Resolução RDC no 12, de 02/01/2001. Regulamento Técnico Sobre os Padrões Microbiológicos para Alimentos. Diário Oficial da União, Brasília, DF, 02 jan. 2001, p.1-54.

BRASIL. Ministério da Agricultura, Pecuária e Abastecimento. Métodos Analíticos Oficiais para Análise.
Microbiológicas para Controle de Produtos de Origem Animal e Água. Instrução Normativa $n^{\circ}$ 62, 26 de agosto de 2003. Diário Oficial da União, Brasília, DF, 18 set. 2003, p. 14.

CAVENAGHI, A. D.; OLIVEIRA, M. N. Influência de algumas características físico-químicas e sensoriais na qualidade de salame tipo italiano fabricado no Brasil.

Revista Nacional da Carne, v. 23, n. 263, p. 44-48, 1999.

CHASCO, J.; LIZASO, G.; BERIAIN, M. J. Cured colour development during sausage processing. Meat Science, v. 44, n. 3, p. 203-211, 1996.

CIROLINI, A. et al. Salame tipo italiano elaborado com culturas starters nativas. Ciência e Tecnologia de Alimentos, v. 30, n. 1, p. 171-179, 2010.

DALLA SANTA, O. R. Avaliação da qualidade de salames artesanais e seleção de culturas starter para a produção de salame tipo italiano. $2008.147 \mathrm{f}$. Tese de Doutorado (Tecnologia em Alimentos). Universidade Federal do Paraná, Curitiba, 2008.

DROSINOS, E. H. et al. Characterization of the microbial flora from a traditional Greek fermented sausage. Meat Science, v. 69, n. 2, p. 307-317, 2005.

FRANCO, B. D. G. M.; LANDGRAF, M. Microbiologia dos Alimentos. São Paulo: Atheneu, 2002.

IBAÑEZ, C. et al. Dry fermented sausages elaborated with Lactobacillus plantarum - Staphylococcus carnosus. Parte II: Effect of partial replacement of $\mathrm{NaCl}$ with $\mathrm{KCl}$ on the proteolytic and insolubilization processes. Meat Science, v. 46, n. 2, p. 277-284, 1997.

LEROY, F.; De VUYST, L. Lactic acid bacteria as functional starter cultures for the food fermentation industry. Trends in Food Science \& Technology, v. 15, n. 3 , p. $67-78,2004$.

MAGRO, G. R.; KLEIN, C. S. Qualidade Microbiológica de Salames tipo Colonial Comercializados na Cidade de Concordia-SC: análise de Salmonella, coliformes totais e termotolerantes. Comunicado Técnico n. 449 (EMBRAPA), Concórdia, Santa Catarina, 2006.

MORETTI, V. A. et al. Chemical and microbiological parameters and sensory attributes of a typical sicilian salami ripened in different conditions. Meat Science, v. 66, n. 4, p. 845-854, 2004.

MILANI, L. I. G. et al. Bioproteção de lingüiça de frango. Ciência e Tecnologia de Alimentos, v. 23, p. 161-166, 2003.

ORDOÑEZ, J. A. P. et al. Tecnologia de Alimentos: Alimentos de origem animal. V. 2. Porto Alegre: Artmed, 2005. 
PHILIPPI, S. T. Nutrição e técnica dietética. São Paulo: Manole, 2003.

SAKHARE, P. Z.; RAO, D. N. Microbial profiles during lactic fermentation of eat by combined starter cultures at high temperatures. Food Control, v. 14, n.4, p. 1-5, 2003.

\section{SAMPAIO, I. B. M. Estatística aplicada à}

experimentação animal. Belo Horizonte: Fundação de Ensino e Pesquisa em Medicina Veterinária e Zootecnia, 1998.

SCHEID, G. A. et al. Avaliação físico-química e sensorial de salame tipo italiano contendo diferentes concentrações de cravo-da-índia (Eugenia caryophyllus.) Ciência

Agrotécnica, Lavras. Edição Especial, p. 1576-1583, 2003.

SIMÕES, M. R. et al. Análise físico-química de linguiças coloniais comercializadas no município de Toledo, Estado do Paraná e comparação com valores fornecidos pelos

fabricantes. Acta Scientiarum Technology, v. 31, n. 2, p. 221-224, 2009.

SIQUEIRA, R. S. Manual de microbiologia de Alimentos. Brasília, DF: Embrapa, 1995.

SOYER, A.; ERTAS, A. H.; ÜZÜMCÜOGLU, Ü. Effect of processing condictions on the quality of naturally fermented Turkish sausages (sucukus). Meat Science, v. 69, n.4, p.135-141, 2005.

\section{STATSOFT INC. Statistica data analysis system version} 7.0. Tulsa: Statsoft Inc., 2004.

TERRA, N. N.; BRUM, M. A. R. Carne e Seus Derivados. São Paulo: Nobel, 1988 .

TERRA, N. N. Apontamentos de Tecnologia de Carnes. São Leopoldo: Unisinos, 2003.

TERRA, A. B. M; FRIES, L. L. M; TERRA, N. N. Particularidades na fabricação de salame. São Paulo: Varela, 2004. 152 p.

VIOTT, A.; STOLBERG, J.; PELISSER, M.R. Qualidade microbiológica e físico-química de salames tipo coloniais da região do Alto Uruguai Catarinense. Revista Higiene Alimentar, v. 20, n. 138, p. 14-21, 2006. 